\title{
Proses Hijrah Muslimah Menuju Kejayaan Islam
}

\section{Tri Lindawati, Mei Sinta, Nindy Dwi, Nungky Andriana}

Universitas Nahdlatul Ulama Sidoarjo

Email: trilinda30@gmail.com

Agama Islam agama yang mentauhidkan akan Allah yang Maha Kuasa yang menguasai seluruh alam yang ada di bumi atau di langit semua akan bergerak sesuai kehendak Allah SWT (Sholichah et al., 2018). Seorang muslimah, hijrah merupakan suatu proses perubahan menuju Allah lebih baik dalam segalah hal yang dilakukan semata-mata untuk kebaikan manfaat dan karna mencari ridho Allah SWT. Karena hijrah adalah sebuah perjalanan hati. hijrah dilakukan dengan bersungguh-sungguh, sedikit demi sedikit dengan belajar beristiqomah dan berani untuk meninggalkan kebiasaan buruk, berani untuk menemukan kebiasan baru dalam segalah hal dengan mengoreksi kepribadiannya. Perlu menetapkan arah tujuan hidup dengan jelas. 
setiap hari, Allah ta'ala menyeru kita bersegerahlah kamu kepada ampunan kepada Tuhanmu. Dibumi ini tempat hijrah yang luas dan rezeki yang banyak, dibutuhkan keberanian untuk berhijrah mengingat betapa besarnya ujian dan rintangan yang akan dihadapi seseorang yang ingin berubah menjadi lebih baik. Karena hijra sangat baik untuk seseorang yang benar-benar ingin merubah, menjadi lebih iman dan bertakwa dengan sungguh-sungguh.

Pemimpin pendidikan harus seperti IImu Nahwu dalam Bahasa Arab yaitu harus bisa Marfu' (dhummah) dan Manshub (fathah), jangan seperti Majrur dan Majzum. Marfu' yang berarti memeluk atau merangkul, sedangkan Manshub yang berarti terbuka tanpa ada yang ditutupi. Jangan seperti Majrur yang berarti menginjak-injak atau merendahkan orang lain. Seperti kata orang dahulu, yaitu Ngeluruk Tanpo Bolo, Menang Tanpo Ngasorake, Sakti Tanpo Aji-Aji, Sugeh Tanpo Bolo (Maula et al., 2017).

Enam langkah berubah menjadi lebih baik, yaitu :

- Rajin mencari ilmu Allah, orang bisa berubah karena mempunyai ilmu, karena dia belajar. Contohnya adalah semenjak mengaji. Orang bisa berhentu mabuk karena tahu hukumnya. Lalu setelah 
mengaji dia berhenti untuk mempermainkan hati wanita, lebih menghormati hak-hak wanita, karena tahu bagaimana mulianya wanita didalam islam. IImu adalah perintah Allah untuk dipelajari. Namun, masalahnya adalah ada beberapa orng yang berilmu namun tidak juga berubah karena tidak diamalkan. Maka langkah berikunya adalah niat.

- Niat dan tekad yang kuat, terkadang kita tidak mau berubah, karena muncul gambaran bahwa melakukannya itu susah. Ada dinding yang membuat kita tidak bisa untuk berubah. Maka, untuk mengahncurkan dinding tersebut kita butuh tekad yang kuat, karena kita akan menghadapi banyak masalah ketika berubah.

- Perhatikan teman-teman pergaulan, kita mau berubah, temannya harus berubah juga. Kalau teman kita peminum, terus kita mau berhenti minum, tapi semua teman kita masih tukang minum, kira-kira apa kita bisa berubah?

Teman sesungguhnya menarik kita pada sebuah keadaan. Jika ingin berubah, carilah terman yang baik.

- Belajar dari pengalaman orang-orang yang berubah, kita bisa belajar dari pengalaman orang-orang yang berubah. 
Dengan kita belajar dari mereka, menimba pengalaman mereka. Semoga kita juga bisa berubah menjadi lebih baik.

- Jangan lelah untuk berdoa, orang yang kalau ingin beubah harus berani untuk berdoa.

- Isi ulang iman kita dengan rutin datang ke majelis taklim, jika ingin berubah, seringseringlah datang ke kajian islam, seringseringlah mampir ketika baterai iman kita mulai habis atau drop. Agar kita selalu mendapatkan petunujuk tentng keislaman dan membuat hati kita semakin mantap menjalankannya. Tidak hanya kita, bahkan para ustadz pun memiliki baterai yang sama dengan kita, kalau sudah mulai drop beliau-beliau juga datang ke tempat kajian. Luar biasa ketika saya mendatangi kajian para ustadz-usradz favorit saya. Rasanya baterai mulai drop langsung full seketika. Seperti disiram habis-habisan. Subhanallah...

Muttaqin (2016) mengatakan Hijrah menurut bahasa berarti meninggalkan, menjauhkan diri dan berpindah tempat. Seseorang dikatakan hijrah jika telah memenuhi dua syarat, yaitu: pertama ada sesuatu yang ditinggalkan dan kedua ada sesuatu yang dituju (tujuan). 
Secara garis besar hijrah terdiri dari dua macam yaitu:

1. Hijrah

Makaniyah

Hijrah Makaniyah yaitu meninggalkan suatu tempat. Selama masa kenabian, peristiwa Hijrah Makaniyah telah terjadi tiga kali, yaitu Hijrah ke Habasya, Hijrah ke Thaif, dan Hijrah ke Madinah.

\section{Hijrah Maknawiyah}

Hijrah maknawiyah pengertianya ditegaskan oleh Nabi Muhammad Saw dalam hadisnya yaitu :

"Seorang muslim adalah seseorang yang menghindari menyakiti muslim lainnya dengan lidah dan tangannya. Sedangkan orang yang berhijrah adalah orang yang meninggalkan semua apa yang dilarang oleh Allah."(Shahih Al Bukhari, Kitabul Iman, Bab 4 Hadis No 10)

Hijrah Maknawiyah dibedakan menjadi empat macam yaitu hijrah I'tiqadiyah, Hijrah Fikriyah, Hijrah Syu'uriyyah, dan Hijrah Sulukiyyah.

\section{Definisi Wanita Muslimah}

Wanita muslimah menurut islam adalah wanita yang menganut agama islam dan 
menjalankan segala kewajiban serta perintah Allah SWT yang terkandung dalam agama islam. Dalam suatu pepatah disebutkan bahwa wanita muslimah adalah perhiasan dunia dan ia lebih mulia daripada bidadari di surga. Menjadi wanita muslimah yang baik hendaknya menjadi cita-cita setiap wanita karena wanita muslimah tentunya disukai Allah SWT dan juga orang-orang disekitarnya.Memang terkadang tidak mudah untuk selalu istiqomah dan menjadi wanita muslimah yang baik, akan tetapi segala hal tersebut layak untuk diusahakan. Untuk menjadi wanita muslimah sejati atau wanita shalehah menurut islam maka ia harus memenuhi segala kewajiban baik sebagai seorang anak, istri, ibu dan peranan lainnya dalam kehidupan.

\section{Kriteria Wanita Muslimah Sejati}

Menjadi wanita muslimah sejati tidaklah begitu sulit seperti yang diperkirakan dan wanita muslimah sejati tentunya memiliki kriteria tertentu. Beberapa kriteria yang mencerminkan bahwa seorang wanita adalah muslimah sejati adalah sebagai berikut. 


\section{Beriman dan bertaqwa kepada Allah SWT}

Harapan yang diinginkan dari seorang hamba dengan mencintai Allah SWT adalah mendapatkan cinta Allah SWT (Purnomo, 2008). Kriteria pertama yang menjadikan seorang wanita sebagai muslimah sejati adalah beriman dan bertaqwa kepada Allah SWT. Wanita muslimah adalah mereka yang senantiasa melaksanakan amar ma'ruf nahi mungkar dan menjalankan segala perintah Allah SWT. Dalam hal keimanan dan ketaqwaan, islam tidak membedakan antara pria dan wanita sebagaimana yang disebutkan dalam firman Allah SWT berikut yang artinya :

"Sesungguhnya laki-laki dan perempuan yang muslim, laki-laki dan perempuan yang mukmin, laki-laki dan perempuan yang tetap dalam ketaatannya, laki-laki dan perempuan yang benar, lakilaki dan perempuan yang sabar, laki-laki dan perempuan yang khusyu', laki-laki dan perempuan yang bersedekah, laki-laki dan perempuan yang berpuasa, laki-laki dan perempuan yang memelihara kehormatannya, laki-laki dan perempuan yang banyak menyebut (nama) Allah, Allah telah menyediakan untuk mereka ampunan dan pahala yang besar." (QS Al Ahzab ; 35) 


\title{
2. Melaksanakan Kewajiban sebagai muslim
}

\begin{abstract}
Sebagai seorang muslimah sejati tentunya seorang wanita harus melaksanakan segala kewajiban sebagai muslim termasuk menjalankan shalat wajib lima waktu maupun puasa ramadhan dan ibadah lain yang diwajibkan atas umat islam. Wanita muslimah juga selalu berusaha untuk melakukan ibadah sunnah yang dianjurkan dan memiliki banyak keutamaan.
\end{abstract}

\section{Menutup aurat}

Seorang wanita wajib menutup auratnya, hal ini dikarenakan wanita adalah makhluk yang dimuliakan Allah SWT dan agar wanita dijauhkan dari fitnah lawan jenisnya. Aurat yang terbuka bisa menyebabkan lawan jenis sulit menjaga pandangan dan menjerumuskan dalam perbuatan zina. Perintah mengenakan hijab dan menutup aurat disebutkan Allah SWT dalam ayat berikut,

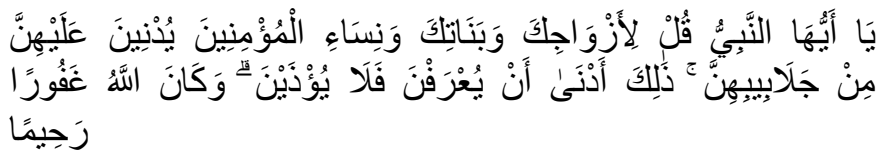


"Hai Nabi, katakanlah kepada isteri-isterimu, anak-anak perempuanmu dan isteri-isteri orang mukmin: "Hendaklah mereka mengulurkan jilbabnya ke seluruh tubuh mereka". Yang demikian itu supaya mereka lebih mudah untuk dikenal, karena itu mereka tidak di ganggu. Dan Allah adalah Maha Pengampun lagi Maha Penyayang. (Qs Al Ahzab : 59)

\section{Memiliki akhlak yang baik}

Akhlak adalah budi pekerti yang ada dalam diri seseorang. Wanita muslimah hendaknya memiliki akhlak yang mulia, tutur kata yang sopan dan perilaku yang santun. Wanita muslimah juga seharusnya memiliki perkataan yang lembut dan tidak berlaku kasar kepada orang lain. Selain itu wanita muslimah juga harus selalu bersabar terhadap apa yang menimpanya dan selalu merasa malu jika berbuat sesuatu yang tidak baik.

Cari ilmu yang bermanfaat dan patuhi aturan-aturan yang ada. Bijaksana dan pantang menyerah dalam belajar adalah kunci kesuksesan. Pendidikan dan Akhlak yang baik melahirkan generasi yang baik juga (Nahdiyah et al., 2017).

\section{Berbakti pada orangtua dan suami}

Berbakti kepada orangtua dan suami adalah kriteria lain dari seorang 
wanita muslimah sejati. Seorang wanita selayaknya menghormati dan berbakti kepada orangtua dan berusaha untuk membantu pekerjaan dan meringankan beban orangtua dalam rumah. Di sisi lainnya, seorang wanita muslimah juga harus berbakti kepada suaminya karena wanita yang tidak berbakti pada suaminya adalah salah satu wanita yang dibenci Allah SWT. Dalam sebuah hadits Rasul SAW bersabda

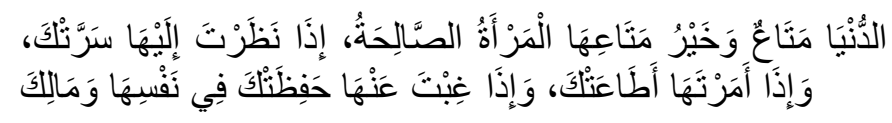

"Dunia ini adalah perhiasan dan sebaik-baik perhiasannya adalah wanita yang shalihah. Bila engkau memandangnya, ia menggembirakan (menyenangkan)mu. Bila engkau perintah, ia menaatimu. Dan bila engkau bepergian meninggalkannya, ia menjaga dirinya (untukmu) dan menjaga hartamu."

\section{Memiliki ilmu dan mampu mengurus keluarganya}

Seorang wanita akan menjadi ibu bagi anak-anaknya dan ia haruslah memiliki ilmu yang bisa ia ajarkan kepada anak-anaknya kelak atau digunakan untuk kemaslahatan masyarakat. Menuntut ilmu hukumnya wajib oleh sebab itu, wanita 
muslimah juga harus menuntut ilmu meskipun tidaklah harus mencapai perguruan tinggi. Asalkan ia bisa merawat anak dan keluarganya dengan baik, maka seorang wanita sudah mampu menjadi muslimah yang baik tentunya jika memnuhi kriteria lainnya.

\section{References}

Maula, I., Mufidah, F.I., Rosyidah, E., \& Purnomo, A. (2017). SD Antawirya Islamic Javanese School Mother is Culture. In Wirausaha Pendidikan Indonesia (Jilid 1). Sidoarjo: Unusida Press.

Nahdiyah, K., Amrina, S., Purnomo, A., \& Rosyidah, E. (2017). SD Taman Pendidikan Islam Porong Iman Kuat Bekal di Akhirat. In Wirausaha Pendidikan Indonesia (Jilid 2). Sidoarjo: Unusida Press.

Purnomo, A. (2008). Bekerja Produktif Berbasis Cinta kepada Allah. In The Spirit of Love Rahasia Bagaimana Cinta Membuat Hidup Lebih Produktif. Yogyakarta: Bukulaela. 
Sholichah, S. A., Asitah, N., Maula, I., Munjidah, A., Nahdiyah, K., Yuniarti, D., Purnomo, A., Rosyidah, E., Achmadi, A. K., Oktawila, D,. \& Anam, F. (2018, May 25). Aksentuasi Islam Berintelektual dan Bersifat Universal. http://doi.org/10.17605/OSF.IO/DXJEA

https://www.muttaqin.id/2016/05/inilah-pengertianhijrah-dalam-sejarah.html

https://dalamislam.com/akhlaq/wanita-muslimahmenurut-islam 